\title{
Understanding the Relationship between Talent Mindset and Organizational Commitment of Employees in Pakistan
}

\author{
Zanoor Haroon, Abideen, Z. ${ }^{*}$ \\ Department of Management Sciences \\ The Islamia University of Bahawalpur, Pakistan \\ *Corresponding author's email: scm170 [AT] hotmail.com
}

\begin{abstract}
----
Purpose:- Talented employees are one of the sources that enable the organizations to achieve competitive advantage. However, considering the globalization and hyper-competition in today's business environment, organizations are facing many challenges including engaging and sustaining talented and skilled employees. Thus, the purpose of this quantitative, correlational, descriptive and cross-sectional study is to understand the relationship between talent mindset (TM) and organizational commitment components (i.e., affective, normative and continuance) of employees in Pakistan.

Design/methodology/approach: The researcher used the quantitative research approach and employed survey based method, using structured verified questionnaires, to collect data from 300 employees (i.e., principals, vice-principals, the chairman, head of the departments and administrative staff) in educational institutions (i.e., privates sector colleges) in two cities (Bahawalpur and Haroonabad) of the Punjab province of Pakistan.
\end{abstract}

Findings: Results confirmed that there is a positive and significant relationship between talent mindset and components of organizational commitment.

Practical Implications/Limitations: This study has considerable importance, because it provided insights regarding the relationship between dimensions of $O C$ with talent mindset by focusing on employees in the services sector of Pakistan. It is also useful as it provided guidelines regarding how the commitment of employees in educational institutions can be enhanced through designing appropriate strategies and frameworks accordingly. In terms of limitations, the present study had small sample size, and focused on employees in services sector in a specific region.

Originality/value: Most of the studies investigating the relationship between TM and dimensions of OC were conducted in the western context and focused on non-services sector. While, this study focused on services sector in non-western context to further the understanding of relationship between talent mindset and components of organizational commitment of employees in educational institutions in Pakistan.

Keywords--- talent mindset, organizational commitment, affective commitment, normative commitment, continuance commitment, educational institutions in Pakistan

\section{INTRODUCTION}

In today's hyper-competitive era, marked by globalization and business competitiveness, among other factors, talented employees are one of the factors that are considered as the lifeline of any business organization, as such employees contribute to successful operations of the organizations, its running, profit-making and a source that enables the organizations to achieve competitive advantage. To Talbot (2016), 'Talent mindset (TM) is a set of actions and faiths that occupy within an institutions and its staffs, which highlights that talented and skilled workers are basic components of competitive edge of an organization'. TM is also termed as a systematic procedure of identifying the vacant positions, hiring the suitable candidates, enhancing and developing their skills and expertise to match with the job requirements and also retaining them to achieve business objectives and goals (Baloch, 2018).

Thus, adopting a talent mindset is essential to achieve competitive advantage through human capital and based on human factor. While, organizations also have the responsibility to make sure that development and growth of their business also develop human capital and talent (Darmanto, 2018). Because, as per Dixit (2017), 'TM is the strong faith that if organization desires to attain their objectives and obtain a competitive edge, talent is required'. Because, competitive advantage is an attribute that allows a company to outperform its competitors. There are three ways to achieve competitive advantage i.e. Cost leadership, Focus and Differentiation. In a cost leadership, the objective is to become the cost leadership, in a differentiation strategy, company's product or services are differentiated from that of its competitors and in a focus strategy, a company focuses on narrow target market segment for its product or services (Hosseini, 2018). 
The concept of organizational commitment - OC (or employee organizational commitment - EOC) has got significant importance and attention. The history of this concept goes back to 1974 when Porter, Steers, Mowday and Boulian established and proposed the theory of OC. The concept of OC is the "relative strength of an individual's identification with, and involvement in a particular organization" (Mowday, Steers, \& Porter, 1979, p. 226, cited in Allen et al., 2018). Moreover, the concept of OC also involves other components including affective, normative and continuance commitment (Dessler, 2017; Kasemsap, 2017; Pindek et al., 2017; Meyer et al., 2002). Where, affective commitment is the psychological attachment and feelings towards their organizations; continuance commitment is the commitment to an organization on account of the expenses/costs associated with leaving the organization, and normative commitment is the moral-obligation that forces an employee to remain in an organization (Malkawi, 2017).

Many authors (e.g., Malkawi, 2017; Mahajan, 2019; Metin, 2018; Zaraket, 2018) have shown that although there is a considerable research studies conducted on the concept of OC, but the relationship between TM and OC remained understudied and unexplored, especially focusing on employees in educational sector in Pakistan as ayub (2017) found in his study that in countries like Pakistan, focus on human resource development (HRD) is not adequate and requires more attention. Therefore, there exist a gap in the literature with regards to the relationship between OC and TM. Thus, the main objective of this research is to understand and empirically examine the relationship between Talent Mindset and components of organizational commitment (i.e., affective, normative and continuance commitment) of employees in educational institutions in the Punjab province of Pakistan.

\section{LITERATURE REVIEW}

Dixit (2017) defined "TM is the strong faith that if organization desires to attain their objectives and obtain a competitive edge, talent is required" (p. 93). Whereas, a competitive advantage is a set of characteristics that allows a company to outperform its competitors. There are three ways of achieving competitive advantage that are Cost leadership, Focus and Differentiation. In a cost leadership, the objective is to become the lowest cost leader. While, in a differentiation strategy, a company's product or services are differentiated from that of its' competitors and a focus strategy enables a company to focus on specific segment of target market (Hosseini, 2018).

The concept of Organizational Commitment has gained popularity in recent years (Darmanto \& Darko, 2018). Akram and Afzal (2011) defined Organizational Commitment as an employee's desire to maintain membership in his organization, willingness to spare no effort in the best interest of the organization, and acceptance of faith in the organizational values and goals. "Organizational Commitment is the relative strength of an individual's identification with and involvement in a particular organization" (Ayaad, 2018, p.766). Considering the multidimensionality of this concept, different authors defined it in different ways. To Kaplan and Kaplan (2018), OC involves three factors i.e., affective commitment (AC), normative commitment (NC) and continuance commitment (CC). Where, AC is one's psychological attachment and affiliation to the organization, $\mathrm{CC}$ is the level to which one believes that quitting the organization would be costly, and finally, NC is the belief that one should remain part of the organization (Grimsely, 2018).

This study holds that the individuals are committed to the organizations as far as they hold their positions, regardless of the stressful condition they experience. However, should they given alternative benefits, they will be willing to leave the organization. This behavioral aspects of organizational commitment is explained through normative and continuance commitment. This continuance and normative commitment refers to an employee's commitment to continue working for the organization based on the notion of leaving an organization (Kaplan \& Kaplan, 2018).

Organizational Commitment has been of widely researched areas in the field of management in relation to different jobs related variables but in Pakistan very few studies have explored this concept. Various researchers identify multiple factors affecting organizational commitment among employees, but present study focuses its relationship with talent mindset to get better performance in the organization of the private sector employees (Warsi, 2017).

Dessler (2017) concluded that Commitment of staff is important for several reasons, it will ultimately reduce employee turnover. Attitude of employees or the motivation to work in relation with job satisfaction and organizational commitment are important in the field of human resource management and organizational behavior perspective.

\section{Talent and Talent Mindset}

Abazeed (2018) defined talent as a set of person's abilities, skills and knowledge. It also involves the ability to learn and grow one's skills and abilities for further development and improvement. As the development of talent changed, so did the definitions of talent. While, the term mindset has different meanings. To Welby-Cooke (2010, p.23), "A mindset can neither be for or against the management of talent, therefore talent mindset be clustered either in terms of new or old mindsets which can have impact on how talent is managed". In this perspective, mindset is a model that transforms thoughts and actions into a belief system that can be seen as a mindset. While, talent mindset can be defined as a comprehensive yet 
integrated approach spanning the whole enterprise and the employee's entire lifespan. Thus, it means something else for each organization (Amin, 2018; Stefko, 2014). According to O'Boyle and Kroska (2017), Talent mindset is often referred as the mindset of the star performers, workforce differentiation, and succession planning. It is also termed as the process through which organization meet their needs for talent in strategic jobs.

Talent and Talent Mindset is important as learning how to manage strategic planning or new product development. This mindset is to believe the organization can outperform its competitors by having better talent. This allow employees to have courage and determination to strengthen their talent through actions (Cappelli, 2017).

Arocas (2017) explained that the organization can enhance and increase the development, effectiveness and productivity level of their employees using better implementations of HR system related to talent and talent mindset plans because talent mindset impacts the performance of organization and focused on talent strategy for return on investments. Talent mindset may be seen as to related with Competency-Based Management (CBM) where abilities are focused on organization's performance, values and goals. Moreover, competencies refer to an individual's demonstrated knowledge, skills or abilities (Mone, 2018). While, such competencies also foster and increase overall productivity and performance of the organization and of its employees. Thus, organizations with talented employees would have more loyalty, commitment and efficiency (London, 2018).

\section{Organizational Commitment}

The concept of organizational commitment is a widely researched and has a multidimensionality as different authors defined it in different ways. Meyer and Allen (1991) defined OC as the intellectual agreement that related to workers to their organization. Whereas, Dessler (2017) stated that "OC is the relative strength of an individual's identification with and involvement in an organization" (p.84). In this research study, researcher defined the OC through its' three components i.e., Affective commitment (AC), Continuance commitment (CC) and Normative commitment (NC). Whereas, "Affective Commitment are defined by emotional attachments, identifications, and involvements to achieve the goal of organization. Continuance Commitment is the willingness to remain in an organization because of different investments. Normative Commitment is defined as the attitude and behavior of the employees" (Tufail, 2015, p.3).

\section{Relationship between Talent Mindset and Organizational Commitment}

Although there are some studies available that examined the relationship between talent mindset and organizational commitment in the western context, but such area focusing on Pakistan remained understudied. Nobarieidishe et al. (2014) examined the relation between TM and $\mathrm{OC}$, and initiate that there is a positive relationship between TM and the components of OC. Thus, considering the relationship between TM and OC, Malkawi (2017) stated that as high performance is driven by higher level of organizational commitment as increased level of organizational commitment will lead to a high level of loyalty, while, loyalty will lead to less costs associated with less turnover rate and increased benefits in terms of productivity, performance, talent development and its retention. Whereas, Abazeed (2018) stated that organizational commitment can be increased through different factors such as leadership behavior, talent development and retention.

Thus, this study tends to investigate the relationship between dimension of organizational commitment and talent mindset. In western context there are many studies are investigated in many ways Malkawi (2017) investigated the relationship between talent mindset and organizational commitment and found that there is a positive relationship between talent mindset and the dimensions of organizational commitment. Makworo and Abok (2014) investigated factors affecting talent mindset. The study indicated that affective, continuance and normative commitment have positive and significantly effect on talent mindset. Other researchers, Kwakye and Otbu (2016) conducted a study on dimensions of organizational commitment and talent mindset, they found that affective commitment would have more commitment only when managers being to create a friendly work environment as they deserve.

In the context of Pakistan, there are few studies that are conducted between talent mindset and organizational commitment. Syed (2016) revealed that this research and the previous studies is the most important property for any organizations. Accordingly, given the research findings, developing talent is key to an organization's success. Therefore, it is important to have a talent mindset aligning with organizational commitment. As mentioned earlier, previous scholars have studied the relationship between and they have conceptualized in different ways, but it is common for all conceptualization that highly committed and talented employees are less likely quit to their jobs (Akram, 2017).

\section{OBJECTIVE OF THE STUDY}

The main objective of this research study is to understand and empirically examine the relation between Talent Mindset and dimensions of Organizational Commitment (i.e. affective, normative and continuance commitment). The sub- 
objective of this study are as follows: (1) To empirically examine the relation between Talent Mindset and affective organizational commitment of employees, (2) To empirically examine the relations between Talent Mindset and continuance organizational commitment of employees, and (3) To empirically examine the relation between Talent Mindset and normative organizational commitment of employees.

\section{HYPOTHESES DEVELOPMENT}

Hypotheses developed are as follows:

H1a $\mathrm{a}_{\mathrm{a}}$ : Affective Commitment of employee organizational commitment is related to Talent Mindset.

$\mathrm{H} 2 \mathrm{a}_{\mathrm{a}}$ : Continuance Commitment of employee organizational commitment is related to Talent Mindset.

H3a $a_{a}$ : Normative Commitment of employee organizational commitment is related to Talent Mindset.

\section{RESEARCH METHODOLOGY AND INSTRUMENTATION}

The research is descriptive, correlational, primary data-based, and quantitative in nature, therefore, data was collected through survey-based approach using close ended structure verified questionnaires by focusing on the employees in the educational sector of Pakistan, therefore, sample consists of all employees (both males and females, academicians and administrators i.e., principals, vice-principals, the chairman, head of the departments and administrative staff) in educational institutions (i.e., privates sector colleges) in two cities (Bahawalpur and Haroonabad) of the Punjab province of Pakistan. For a good sample size, normally a 95\% confidence level is used that mean there is a chance of 5\% that the result of the study can differ from the actual ones. Thus, for calculating of sample size, researcher treating 700 employees as a population size, having $95 \%$ confidence interval and the error margin of $5 \%$ results in sample size of 248 . Therefore, researcher has used non-probability convenience sampling because of the limitations in the availability of the participants. In this study, verified structured questionnaire were used to collect data from the respondents. Talent Mindset is labelled as the dependent variable, while dimensions (i.e., affective commitment, normative commitment and continuance commitment) of organizational commitment were labelled as independent variables in the present study. Regarding the measurement of OC, Meyer and Allen questionnaire of organizational commitment was used. The OC scale has 15 items (5 items for each dimensions). The calculated reliability coefficient i.e. Cronbach's alpha for Affective Commitment was calculate as 0.910, for Continuance Commitment was 0.85, and for Normative Commitment was 0.745 (Mugizi et al., 2015). While all three values exceeded the level of 0.70 as proposed by Nunnally (1978). Regarding the other variable, Talent Mindset, the researcher used the Talent Mindset Index-TMI (2003) of Human Capital Institute to measure talent mindset in the institute. This scale has total 28 items. The Cronbach's Alpha was calculated as 0.960 for the 28 items and this is considered as an acceptable reliability for the TMI as it exceeds the level of 0.70 as suggested by the Nunnally (1978).

\section{DATA ANALYSIS}

The data was analyzed using different statistical tools and techniques including descriptive statistics, correlation and multiple regression. Cronbach's alpha, the Kaiser-Meyer-Olkin (KMO) test and the Bartlett's test of Sphericity was also used.

Cronbach's Alpha:

Table 1 : Reliability Value of Measurement Instrument

\begin{tabular}{|l|c|c|}
\hline Scales & No. of Items & Cronbach's Alpha (Calculated) \\
\hline Affective Commitment & 5 & 0.85 \\
\hline Normative Commitment & 5 & 0.79 \\
\hline Continuance Commitment & 5 & 0.81 \\
\hline Talent Mindset & 28 & 0.695 \\
\hline
\end{tabular}

Source: Author's Computation using SPSS. 
In the table 1, the Cronbach's alpha values of each variable under studied (i.e., TM and three dimensions of OC) were calculated using the software SPSS. The value of Cronbach's alpha for each variable is quite satisfactory and exceeds the threshold value of 0.70 as suggested by Nunnally (1978).

\section{The Kaiser-Meyer-Olkin (KMO) and the Bartlett's test of Sphericity:}

The results of the KMO and Bartlett's test of Sphericity shown that the measurement of the Kaiser-Meyer-Olkin yielded the value of 0.74 . Because Kaisen (1974) recommended 0.5 as minimum (barely accepted), values between 0.7 0.8 as acceptable, and values above 0.9 as perfect. While, Bartlett's test of sphericity also indicated satisfactory and acceptable results.

\section{Multicollinearity:}

The outcome of the said test can be seen in the table 2. The result shows that highest value for VIF is 1.624 , which is quite less than standard value of 5 of VIF in multicollinearity. In case of TOL, all values are greater than 0.2 , which states the result are satisfactory and confirm the lack of multicollinearity amongst the independent variables.

Table 2: Multicollinearity Statistics

\begin{tabular}{|c|l|l|}
\hline \multirow{2}{*}{ Model } & \multicolumn{2}{|l|}{ Collinearity Statistics } \\
\cline { 2 - 4 } & Tolerance & VIF \\
\hline \multirow{2}{*}{ Affective Commitment } & 0.743 & 1.555 \\
Normative Commitment & 0.716 & 1.624 \\
Continuance Commitment & 0.812 & 1.231 \\
\hline
\end{tabular}

a. Dependent Variable: Talent Mindset

\section{Correlation Analysis}

Pearson correlation was run to check the relation of variables with each other and to determine if any variable has perfect covariance with other variable (Cooper, 2018). The most correlated variable is Affective Commitment with TM, as it has the correlation coefficient value of 0.584 with sig. value of 0.000 , that is $r(250)=0.584, p=0.000$. Thus, it can be said that there is a positive but moderate relationship between AC and TM. The second most correlated variable is Continuance Commitment that has the correlation value 0.595 at sig. value of 0.000 , that is $r(250)=0.595, p=0.000$. Thus, it can be said that there is a positive but moderate relationship between CC and TM. The third most correlated value is Normative Commitment that has the correlation value 0.555 at sig. value of 0.000 , that is $r(250)=0.555, p=0.000$. Thus, it can be said that there is a positive but moderate relationship between NC and TM. Summing up, all three dimensions and OC itself has positive relationship with the concept of talent mindset. Therefore, there is a positive but moderate relationship between the variable under investigations.

\section{Hypotheses testing using Multiple Regression:}

The proposed hypotheses were tested using multiple regression analysis.

\section{First Hypothesis:}

$H 1 a_{a:}$ Affective component of employee organizational commitment is related to talent mindset.

Research Hypothesis H1a states that affective commitment of employee organizational commitment is related to talent mindset. Regression analysis predicting the proposed relationship is statistically significant, thus, it can be said that affective component of employee organizational commitment is positively related to Talent Mindset, as $F(8,254)=145.010$, $p=0.000$. Thus, this hypothesis is accepted as $\mathrm{p}<0.05$. 


\section{Second Hypothesis:}

$H 2 a_{a}$ : Normative component of employee organizational commitment is related to Talent Mindset.

Research Hypothesis H2a states that normative commitment of employee organizational commitment is related to talent mindset. Regression analysis predicting the proposed relationship is statistically significant, thus, it can be said that normative component of employee organizational commitment is positively related to Talent Mindset, as $\mathrm{F}(8,254)=145.010, p=0.000$. Thus this hypothesis is accepted as $\mathrm{p}<0.05$.

\section{Third Hypothesis:}

H3a $:$ Continuance component of employee organizational commitment is related to Talent Mindset.

Research Hypothesis H3a states that continuance commitment of employee organizational commitment is related to talent mindset. Regression analysis predicting the proposed relationship is statistically significant, thus, it can be said that continuance component of employee organizational commitment is positively related to Talent Mindset, as $\mathrm{F}(8,254)=145.010, p=0.000$. Thus, this hypothesis is accepted as $\mathrm{p}<0.05$.

\section{DISCUSSION AND CONCLUSION}

As the study was conducted to understand and empirically examine the relationship between Talent Mindset and Organizational Commitment, therefore, it also helped to find the relative importance of these organizational commitment components on talent mindset. The researcher concluded that the result of the correlations analysis showed that all OC dimensions under investigation have positive but moderate relationship with talent mindset. The findings do confirm that organizational commitment is not only a multi-dimensional concept, but it also get influenced by lots of others factors not currently covered by this study. From the study findings, it can be concluded that organizational commitment is very important for any educational institution. This is because in order to increase the efficiency, effectiveness, productivity and commitment of employees, some programs and talent mindset strategies and talented models should be properly launched and to increase the productivity of employees in educational sector by focusing and improving organizational commitment through talent mindset strategies.

This research was conducted in Pakistan, specifically focusing on employees in educational sector, to understand and empirically investigate the relationship between organizational components (affective commitment, normative commitment and continuance commitment) and talent mindset. The components of OC whose names are affective, normative and continuance commitment are positively related to talent mindset. This is because in order to increase efficacy, productivity, effectiveness and commitment of employees, some strategies should be launched by focusing organizational commitment through talent mindset strategies. The first hypothesis was related to empirically investigate the relationship between talent mindset and affective commitment. The second hypothesis was related to empirically investigate the relationship between talent mindset and normative commitment. The third hypothesis was related to empirically investigate the relationship between continuance commitment and talent mindset.

\section{RECOMMENDATIONS FOR FUTURE RESEARCH AND LIMITATIONS:}

Future study should focus on both public and private sector educational institutions in different provinces of Pakistan to have more in-depth results in comparative form. While, some ways should be devised to ensure a high response rate in educational institutions for the study. Furthermore, longitudinal research studies can also be considered to better know the effects of any talent mindset programs on the organizational commitment of employees. The study has following limitations: (1) The research instrument of the present study was self-administrated, therefore, informant-based instrument can yield further insights, (2) time and cost were also a restraint and (3) The sampling frame for the present study was limited to only Muslim employees in Punjab Province only.

\section{REFERENCES}

- $\quad$ Abazeed, R. A. M. (2018). The Impact of Talent Management on Organizational Commitment of the Employees of Telecommunication Companies in Jordan: The Mediating Role of Employee Work Engagement. International Journal of Academic Research in Accounting, Finance and Management Sciences, 8(4), 153-162.

- Akram, M., Afzal, U., \& Ramay, M. I. (2017). Mediating role of Organizational Commitment in relationship between emotional intelligence and job performance: Evidence from Higher Education sector of Pakistan, 7(1). 
- Ali, M. H. (2018). The effect of job satisfaction on the organizational commitment of teachers, with special reference to private-sector universities of Punjab, Pakistan.

- Alziari, L. (2017). A chief HR officer's perspective on talent management. Journal of Organizational Effectiveness: People and Performance, 4(4), 379-383.

- Barkhuizen, E. N. (2014). Project talent management. Project management: A behavioral perspective: Theoretical principles, advanced practices and cases. Pearson Education, 370-408.

- Baker, D. T., \& Kelan, E. (2017). Integrating Talent and Diversity Management. In The Oxford Handbook of Talent Management.

- Barkhuizen, N., Mogwere, P., \& Schutte, N. (2014). Talent management, work engagement and service quality orientation of support staff in a higher education institution. Mediterranean Journal of Social Sciences, 5(4), 69.

- Cappelli, P., \& Keller, J. R. (2017). The historical context of talent management. The Oxford handbook of talent management, 23-42.

- Collings, D. G., \& Mellahi, K. (2009). Strategic talent management: A review and research agenda. Human resource management review, 19(4), 304-313.

- Collings, D. G., Mellahi, K., \& Cascio, W. F. (Eds.). (2017). The Oxford handbook of talent

- Devender, V. (2013). Human resource planning practices in SCCL. VSRD International Journal of Business and Management Research, 3(9), 373-382.

- Dixit, S. (2017). A Study of Current Talent Management Strategies for Employee Engagement of Public Sector Banks in Rajasthan.

- Maurya, K. K., \& Agarwal, M. (2018). Organisational talent management and perceived employer branding. International Journal of Organizational Analysis, 26(2), 312-330.

- Kaplan, M., \& Kaplan, A. (2018). The Relationship between Organizational Commitment and Work Performance: a Case of Industrial Enterprises. Journal of Economic and Social Development (JESD), 5(1), 46-50.

- Malkawi, E. (2017). The Relationship Between Talent Management and Organizational Commitment Case Study: Aqaba Special Economic Zone Authority, Jordan. International Business and Management, 14(1), 80-84.

- Meyer, K. E., \& Xin, K. R. (2018). Managing talent in emerging economy multinationals: Integrating strategic management and human resource management. The International Journal of Human Resource Management, 29(11), 1827-1855.

- Meyers, M. C., \& Van Woerkom, M. (2014). The influence of underlying philosophies on talent management: Theory, implications for practice, and research agenda. Journal of World Business, 49(2), 192-203.

- Morgan, H., \& Jardin, D. (2010). Integrated talent management. OD PRACTITIONER, 42(4), 24.

- Morton, L. (2005). Talent Management: A Critical Way To Integrate \& Embed Diversity. Available from: http://www. workinfo. com/free. Downloads/259. htm.

- Muriithi, F. W., \& Makau, M. (2017). Talent Management: A Conceptual Framework from Review of Literature and a Research Agenda. Journal of Human Resource Management, 5(6), 90-94.

- Nobarieidishe, S., Chamanifard, R., \& Nikpour, A. (2014). The relationship between talent management and organizational commitment in international division of Tejarat Bank, Iran. European Online Journal of Natural and Social Sciences, 3(4), 1116.

- Schiemann, W. A. (2014). From talent management to talent optimization. Journal of World Business, 49(2), 281288.

- Stefko, R., \& Sojka, L. (2014). Position of talent management in context of organizational functions. European Scientific Journal, ESJ, 10(10).

- Welby-Cooke, G. (2010). The psychometric properties of a talent mindset index (Doctoral dissertation, University of Pretoria). 